\title{
Impact of the professional exposure on the spermatic parameters and the results of ICSI at Tunisian unfertile couples
}

\author{
Habib Ben Ali $^{{ }^{*}}$, Monia Zaouali ${ }^{2}$, Fatma Atig ${ }^{1,3}$, Iheb Bougmiza ${ }^{4}$, Souhir Mehri ${ }^{3}$, \\ Houda Ben Frej ${ }^{5}$, Faten Tabka ${ }^{5}$, Ali Saad ${ }^{1,3}$, Mounir Ajina ${ }^{1,3}$ \\ ${ }^{1}$ Laboratoire de Cytogénétique, Génétique Moléculaire et Biologie de la Reproduction Humaines, CHU Farhat Hached de Sousse, \\ Sousse, Tunisie; *Corresponding Author: alihabibsaoudite@yahoo.fr \\ ${ }^{2}$ Laboratoire de Physiologie et des Explorations Fonctionnelles, Faculté de Médecine de Sousse, Sousse, Tunisie \\ ${ }^{3}$ Unité de Médecine de la Reproduction, CHU Farhat Hached de Sousse, Sousse, Tunisie \\ ${ }^{4}$ Service de Médecine Communautaire, Faculté de Médecine de Sousse, Sousse, Tunisie \\ ${ }^{5}$ Service de Médecine de Travail, CHU Farhat Hached de Sousse, Sousse, Tunisie
}

Received 6 August 2013; revised 14 September 2013; accepted 3 October 2013

Copyright (C) 2014 Habib Ben Ali et al. This is an open access article distributed under the Creative Commons Attribution License, which permits unrestricted use, distribution, and reproduction in any medium, provided the original work is properly cited. In accordance of the Creative Commons Attribution License all Copyrights (C) 2014 are reserved for SCIRP and the owner of the intellectual property Habib Ben Ali et al. All Copyright (C) 2014 are guarded by law and by SCIRP as a guardian.

\section{ABSTRACT}

Introduction: The association of the professional exposure to the decline of the male reproductive function had been the subject of several studies but without arriving to one envisagement undeniable of its existence. The ICSI, technique of reference in severe male infertilities, is vis-a-vis unexplained failures whose environmental and professional exposure could be about its cause partly. In this work, we tried to highlight an association between certain factors of professional exposure and the deterioration of the spermatic parameters, then to evaluate the effect of such factors on the result of the ICSI. Materials and Methods: It is about a study of the exposed type-no exposed, realized through collaboration between the Unit of Medicine of the Reproduction and the Service of Medicine of Work of the CHU Farhat Hached of Sousse. This study was based on a questionnaire of which part of the items was collected medical files of the patients raising the general characteristics, the profile of exposure as well as the spermatic parameters and the biological assessment of ICSI. Results: Significant associations between the deterioration of sperm and the professional risk factors such as the exposure to the formaldehydes $(p=0.01)$ and heat $(p$ $=0.001$ ) were noted. The exposure to formaldehydes was associated at the higher risk of oli- gozoospermy, of asthenozoospermy with a significant reduction in mobility $(p=0.05)$, whereas the talks with cement had a risk higher of teratozoospermy. In addition an exposure to heat was associated at the high risk of oligoteratozoospermy. The total rate of pregnancies after ICSI among 220 patients of our series was of $14.47 \%$. The ICSI balance showed a reduction in total fertility rate $(76.6 \%$ exposed vs $75.3 \%$ no exposed). Conclusion: In spite of the limited number of the patients, this study had shown a correlation between certain professional exposures of origin and the deterioration of sperm. They are preliminary results which encourage continuing collaboration between the specialists in the reproduction and the doctors of work in order to preserve the fertility of the workers exposed to factors gonadotoxic.

\section{KEYWORDS}

Male Sterility; Professional Exposure; Spermogramm; ICSI

\section{INTRODUCTION}

In the industrialized countries, $15 \%$ of couples find it difficult to conceive naturally [1]. The male factor is involved in half of these couples and the etiology remains unknown in $25 \%$ of cases [2]. As the medical history cannot explain all the cases of male infertility, these 
observations can be associated with an increasing incidence of the occupational and environmental factors. This is the reason why one priority in these countries consists in identifying such factors and reducing the number of infertile couples with preventive means.

Since men are frequently exposed to various chemical and physical agents at the same time, several studies have analyzed the relationships between the occupational environment and the sperm quality by means of different epidemiological methods. Many studies were carried out about specific [3] or occupational [4] exposures. In these studies, the data are accurately collected about one risk factor with sub categories [5] or the intensity of the physical agent [6]. However, collecting the data is most often costly and time-consuming, these studies are carried out when a factor has already been suspected. Conversely, general questionnaires on the occupational exposure can be used in order to identify the risk factors. Some are self programmed [7], others are indicated by the physicians in the infertility centers [8]. Most of them are questionnaires aimed at assessing the new sperm alteration risk factors.

In this context, we used a questionnaire to obtain information about the occupational exposures through a self statement. This allows to assess the associations between the occupational exposures, the sperm quality and the traditional markers of the ancillary glands in males who consulted in the reproductive medicine unit in the Teaching Hospital in Sousse. As a matter of fact, studies have shown that exposure to toxic products is associated with a decrease in sperm count, spermatozoon motility and an increase in spermatic DNA fragmentation $[9,10]$. Although these studies indicate an effect of exposure to chemicals on the sperm parameters, the control mechanisms are still unknown. One possible explanation could show an indirect effect of these products on spermatogenesis through ( $\alpha$ and $\beta$ ) oestrogens or by other receptors. However, it has been demonstrated that the epididymis and the ancillary glands are among the organs that may modulate the sperm motility and the integrity of spermatic DNA [11,12]. These organs are strongly regulated by the sex hormones and present receptors for the androgens and the oestrogens [13] and they are also targets of the chemicals. However, there is little information concerning the mode of action of the chemicals on the function of the epididymis and the ancillary glands. The neutral $\alpha$ glucose-dase, citric acid and fructose are released in the seminal plasma. These excretory products are traditionally used as seminal markers of the organs posterior to the testicles. On the other hand, the effect of the occupational exposure on the fertilizing capacity of the spermatozoa ([14] and the study of pregnancies obtained by IVF or ICSI represent an interesting pattern for the influence of the paternal risk factors on the results of the medically assisted procreation. In order to study the consequences of some occupational exposures on the sperm parameters on the one hand, and the results of ICSI on the other, we conducted a study within a hospital (Teaching Hospital, Sousse).

\section{MATERIAL AND METHODS}

In this study, 250 subjects were enrolled from January to June 2012 among the couples consulting for infertility in the reproductive medicine unit in the teaching Hospital in Sousse. These are the inclusion criteria of the participants:

- Age between 30 and 55 .

- Resident in the Sousse area referred for investigation of the couple's infertility.

- Absence of an identifiable cause of male infertility (that is, bilateral cryptorchidism, bilateral testicular hypotrophy, varicocele, congenital absence of the seminal ducts, hypogonadotrophic hypogonadism, radiation therapy or chemotherapy history, genetic or chromosomal abnormality).

- Absence of use of medicines known for their adverse effect on the sperm parameters.

25 men were excluded from this survey because the criteria were not met. 23 were excluded because of identifiable causes of infertility and 2 others refused to participate in this study.

These patients are interviewed and answer a four-part questionnaire:

1) The first part includes general information: age, place of birth, address, rural area, urban area.

2) The second part deals with the risk factors known for their disruptive effect on the sperm parameters, including the history of genital disease (mumps, cryptorchidism, orchitis, testicular torsion, scrotal trauma, unilateral varicocele, surgery for inguinal hernia in childhood and genital tract infections), high fever $\left(\geq 38^{\circ} \mathrm{C}\right)$ in the previous 3 months, hot baths ( $\geq 1 /$ week).

3) The third part is devoted to lifestyle: consumption of tobacco, alcohol or marijuana.

4) The fourth part assesses the subjects' occupational exposure using 3 parameters: the socioeconomic class, the subjects' occupation and the exposure considering the exact professional activity.

The chemicals that were sought on the workplace were the heavy metals, pesticides, formaldehydes, cement, fumes and temperature. A subject is considered to be exposed to gases and fumes if he is exposed to at least one of the following elements: plastic vapors, engine fumes, vegetables steam, welding fumes or metal industry vapors (separate questions).

Individuals exposed to welding fumes are regarded to be exposed to heavy metals. Among the chemicals mentioned by the patients, cement is noted and analyzed. 
Exposure to a chemical is considered positive when the recent exposure is superior or equal to one hour/week since 3 months or more. If the exposure is ancient, it has to have lasted one year or more with a frequency of one hour a week. An exposure to physical agents is positive only if it has lasted one hour a week for 3 months or more.

A written consent of each subject was taken after explaining the aims and objectives of the study and its benefits on individual and society. Also, the study was approved by the Local Ethic Committee of the Farhat Hached University Hospital, Sousse (Tunisia).

\subsection{Sperm Test}

The ejaculates are collected by masturbation in sterile flasks after sexual abstinence of 2 to 5 days. Spermogrammes are performed after 30-minute liquefaction at $37^{\circ} \mathrm{C}$. The test includes volume, $\mathrm{pH}$, viscosity, count, motility and morphology of the spermatozoa according to the WHO standards [15]. Based on these standards, the sperm quality is considered normal if the following three parameters are normal: + Total count of spermatozoa $\geq 40 \times 10 \mathrm{spz} /$ ejaculate (opposite case: oligospermia) Spermatozoon motility $[(a+b) \geq 50 \%$ or $(a) \geq 25 \%$ ] (opposite case: slow sperm mobility) + Morphology of spermatozoa $\geq 30 \%$ (opposite case: teratospermia) according to David's modified classification [16,17].

\subsection{Ovarian Stimulation and Oocyte Retrieval}

The details of the stimulation protocol using GnRH (acetatebuserelin, Suprefact spray; Hoechst, Frankfurt, Germany), human menopausal gonadotrophins (Humegon; Organon, Oss, The Netherlands; Pergonal; Serono, Aubonne, Switzerland) and human chorionic gonadotrophins (Pregnyl; Organonb; Profasi; Serono), the puncture of the ovocytestransvaginally under ultrasonography control; the embryonic culture and the transfer of the embryos are described elsewhere [18].

\subsection{Oocyte Preparation}

Immediately after oocyte puncture, cumulus oophorus and corona radiata are eliminated by incubation of the oocytes in an Eagles medium containing $60-80 \mathrm{IU} / \mathrm{ml}$ hyaluronidase (Type VIII; Sigma, St Louis, USA) for one minute. The few remaining cells of the corona radiata are removed manually with glass pipettes. The ovocytes are examined under inverted microscope to check the presence of the first polar body. The ovocytes remain incubated for 3 to 4 hours and ICSI is performed for all the ovocytes with the first polar body.

\subsection{Sperm Preparation}

Sperm used for ICSI is prepared with a discrete densi- ty gradient PureSperm (Nidacon, Goteborg, Sweden). The discrete density gradient is made up of three layers of $1 \mathrm{ml}$ PureSperm: $90 \%, 70 \%$ and $50 \%$. $1 \mathrm{ml}$ of sperm is deposited on the $50 \%$ layer. The gradient is then centrifuged at $300 \mathrm{~g}$ for 20 minutes. After centrifugation, the $90 \%$ layer is collected and washed with $5 \mathrm{ml}$ Ferticult Flushing (Ferti Pro N.V, Beermen, Belgium) at $400 \times \mathrm{g}$ for 10 minutes. The processed sperm is suspended in the IVF medium (Scandinavian IVF, Goteborg, Sweden).

\subsection{Sperm Injection in the Oocyte}

The selected spermatozoon is deposited in a thick liquid medium (polyvinylpyrrolidone, PVC), which allows to slow down the movement of the spermatozoon, and immobilize it later. With a micropipette the spermatozoon is aspired, starting with the flagellum, then it is injected in the plasma of the ovocyte which is held by another containment micropipette where the first polar body is oriented in diametrically opposed way.

\subsection{Assessment of Fertilization, Segmentation and Pregnancy}

The presence of two pronuclei appears 18 hours following injection. The ovocytes are fertilized if they have two clear pronuclei. Segmentation occurs 42 hours and an estimate score is granted to all embryos. This score is based on the presence of the anucleated cytoplasmic fragments, the regularity and the number of blastomereswith a maximum of 6 points per embryo [19]. Three embryos at most are transferred. Pregnancies are diagnosed by at least two positive dosages of $\beta$ HCG ( $>1 \mathrm{~m}$ $\mathrm{IU} / \mathrm{ml}$ ) (Behring Inc, Behring, Germany) over three separate days, starting on the 11th day of puncture. The clinical pregnancy was confirmed by ultrasonography 5 weeks after puncture.

\subsection{Statistical Study}

The statistical study is carried out with the SPSS 16.0software. We resorted to parametrical tests: Student's $t$ test is used for the comparison of averages; the Chi 2 test is used for the comparison of percentages. Non parametrical tests, such as Fischer's exact test and MannWhitney's test are also used. The significance threshold is set at $5 \%(\mathrm{p}<0.05)$ and the Odds Ratios (OR) are estimated with the confidence intervals to $95 \%$.

\section{RESULTS}

\subsection{Overall Investigation}

The males, whose sperm is altered, have shown the same demographic characteristics as those with normal sperm. The participants are mainly construction workers and workers in the administrative departments. The sub- 
jects from the medium class have a low risk of sperm alteration in relation to subjects from other classes. Conversely, the workers and clerks have a higher risk of sperm alteration compared to the other social and economic classes; $\mathrm{p}=0.01$ and $\mathrm{p}=0.02$ respectively. The professional sector is not related to the sperm quality. The influence of occupational exposures on sperm quality is recorded by comparing the effect of exposure to chemical and physical factors between individuals with altered sperm or with normal one. In the univariate analyses, males with altered sperm were much more frequently exposed to each chemical agent than males with normal sperm: heavy metals OR $=3.4$; IC 95\%, 1.6 $18.1 ; \mathrm{p}=0.07)$, pesticides (OR = 2.6; IC 95\%; 1.8 - 15.1), fumes $(\mathrm{OR}=1.9$; IC 95\%; $1.1-3.6$; $\mathrm{p}=0.06)$. This association is significant for formaldehydes $(\mathrm{OR}=2.5$; IC 95\%; 1.4 - 4.5; $\mathrm{p}=0.04)$ and for cement $(\mathrm{OR}=2.5$; IC $95 \% ; 0.84-6.4 ; \mathrm{p}=0.05)$. Among the different exposures to fumes, it was observed that exposure to welding fumes was more frequent in males with altered sperm than in those with normal sperm. No association between the physical factor and sperm quality was found.

\subsection{Parameters of Isolated Sperm}

Tables 1 and 2 give a comparison of the sperm parameters between individuals exposed and not exposed to occupational factors known in the literature for their sperm -disturbing effect. Most sperm alterations were found in our survey:

1/A higher risk of slow sperm mobility [asthenospermia] (OR = 2.87; Ic 95\%; 0.35 - 23.86) in subjects exposed to heavy metals;

2/A higher risk of oligospermia (OR $=0.93$; IC 95\%; 0.2 - 4.24), of slow sperm motility (OR = 1; IC95\%; 1.19 - 519, motility and morphology disorders in the individuals exposed to pesticides.

3/A higher risk of oligospermia (OR = 1.39; IC95\%; 0.62 - 3.11) and alterations of the total sperm count in those exposed to formaldehydes.

The other chemicals were recorded by the occupational doctor even if they are not known to be toxic for reproduction. Exposure to cement proved to be correlated to a higher risk of teratospermia (OR = 1.64; IC95\%; 0.71 - 3.7), alteration of sperm motility and morphology.

Table 1. Comparison of the averages of the sperm parameters between exposed and unexposed.

\begin{tabular}{|c|c|c|c|c|c|c|c|}
\hline $\begin{array}{c}\text { Factor } \\
\text { exposure }\end{array}$ & Study population & $\begin{array}{c}\text { Count }\left(\times 10^{6} / \mathrm{ml}\right) \\
\text { mean }( \pm \mathrm{SD})\end{array}$ & $\mathrm{p}^{*}$ & $\begin{array}{l}\text { Mobility (\%) } \\
\text { Mean ( } \pm \text { SD) }\end{array}$ & $\mathrm{p}^{*}$ & $\begin{array}{c}\text { Abnormal forms }(\%) \\
\text { Mean }( \pm S D)\end{array}$ & $\mathrm{p}^{*}$ \\
\hline Formaldehyde & $\begin{array}{c}\text { Exposed }(n=24) \\
\text { Unexposed }(n=130)\end{array}$ & $\begin{array}{l}54.6 \pm 4.5 \\
67.8 \pm 8.1\end{array}$ & 0.4 & $\begin{array}{l}16.1 \pm 1.2 \\
26.8 \pm 1.2\end{array}$ & 0.05 & $\begin{array}{l}74.1 \pm 1.3 \\
72.1 \pm 1.5\end{array}$ & 0.5 \\
\hline Pesticides & $\begin{array}{c}\text { Exposed }(n=5) \\
\text { Unexposed }(n=130)\end{array}$ & $\begin{array}{l}89.9 \pm 6.2 \\
65.5 \pm 7.3\end{array}$ & 0.5 & $\begin{array}{l}28.6 \pm 1.1 \\
24.9 \pm 1.1\end{array}$ & 0.5 & $\begin{array}{l}73.3 \pm 1.1 \\
72.2 \pm 1.4\end{array}$ & 0.8 \\
\hline Ambient heat & $\begin{array}{c}\text { Exposed }(n=31) \\
\text { Unexposed }(n=130)\end{array}$ & $\begin{array}{l}48.6 \pm 7.5 \\
69.7 \pm 9.7\end{array}$ & 0.1 & $\begin{array}{l}22.7 \pm 1.7 \\
25.5 \pm 1.3\end{array}$ & 0.3 & $\begin{array}{l}75.3 \pm 1.6 \\
71.7 \pm 1.6\end{array}$ & 0.2 \\
\hline $\begin{array}{l}\text { Metals } \\
\text { heavy }\end{array}$ & $\begin{array}{c}\text { Exposed }(n=7) \\
\text { Unexposed }(n=130)\end{array}$ & $\begin{array}{l}29.3 \pm 2.6 \\
67.6 \pm 8.6\end{array}$ & 0.2 & $\begin{array}{l}17.5 \pm 1.8 \\
25.3 \pm 1.2\end{array}$ & 0.2 & $\begin{array}{l}78.3 \pm 1.2 \\
72.1 \pm 1.5\end{array}$ & 0.3 \\
\hline Cement & $\begin{array}{c}\text { Exposed }(n=22) \\
\text { Unexposed }(n=130)\end{array}$ & $\begin{array}{l}73.4 \pm 6.6 \\
65.2 \pm 5.8\end{array}$ & 0.6 & $\begin{array}{l}24.5 \pm 1.5 \\
25.1 \pm 1.4\end{array}$ & 0.8 & $\begin{array}{l}73.6 \pm 1.8 \\
72.1 \pm 1.1\end{array}$ & 0.6 \\
\hline smoke & $\begin{array}{c}\text { Exposed }(n=6) \\
\text { Unexposed }(n=130)\end{array}$ & $\begin{array}{l}17.8 \pm 9.5 \\
67.8 \pm 8.4\end{array}$ & 0.1 & $\begin{array}{l}20.1 \pm 1.3 \\
25.2 \pm 1.3\end{array}$ & 0.4 & $\begin{array}{l}80.1 \pm 1.9 \\
72.1 \pm 1.5\end{array}$ & 0.2 \\
\hline
\end{tabular}

p: sueil significance $\leq 5 \%$.

Table 2. Comparison of semen parameters between exposed and non-exposed to occupational factors that may affect the sperm characteristics.

\begin{tabular}{|c|c|c|c|c|c|c|}
\hline Factor exposure & $\begin{array}{l}\text { Oligozoospermia } \\
\text { OR (95\% IC) }\end{array}$ & $\mathbf{p}$ & $\begin{array}{l}\text { Asthenozoospermia } \\
\text { OR (95\% IC) }\end{array}$ & $\mathbf{p}$ & $\begin{array}{l}\text { Teratozoospermia } \\
\text { OR (95\% IC) }\end{array}$ & $\mathbf{p}$ \\
\hline Formaldehyde $(n=24)$ & $1.3(0.6-3.1)$ & 0.4 & $1.4(0.5-3.7)$ & 0.4 & $1.4(0.6-3.3)$ & 0.3 \\
\hline Pesticides $(n=5)$ & $0.9(0.2-4.2)$ & 1 & $1(0.1-5.2)$ & 1 & $0.9(0.2-4.2)$ & 1 \\
\hline Ambient heat $(n=31)$ & $1.4(0.7-3.0)$ & 0.2 & $1.0(0.5-2.4)$ & 0.8 & $1.2(0.6-2.6)$ & 0.5 \\
\hline Cement $(n=22)$ & $1(0.4-2.2)$ & 0.9 & $1.1(0.4-2.5)$ & 0.9 & $1.6(0.7-3.7)$ & 0.2 \\
\hline Smoke $(n=6)$ & $3.2(0.6-6.9)$ & 0.2 & $0.4(0.2-3.7)$ & 0.6 & $4.3(0.5-3.7)$ & 0.2 \\
\hline
\end{tabular}

OR: Odds Ratio; IC: confidence interval; p: seuil significance $(<5 \%)$. 
As for the physical risk factors, we noticed a greater risk of oligospermia (OR = 1.47; IC95\%; 0.72 - 3.02), of teratospermia (OR = 1.27; IC95\%; 0.61 - 2.67), alteration of sperm motility and morphology in subjects exposed to high temperatures. In individuals exposed to excessive heat, we found more men with slow sperm mobility (asthenospermia). Finally, we found a very high risk of progressive sperm motility in the subjects exposed to heat during prolonged periods per week $(>20$ hours/week).

\subsection{ICSI Check Up}

\subsubsection{Fertilization}

There is a slight decrease in the mean fertilization rate in those exposed compared to those not exposed (67.6\% vs $75.3 \%$ ). Among the exposure factors, only formaldehydes showed a slight decrease in the fertilization rate in the exposed individuals (OR = 1.89; IC95\%; 0.71 - 5).

\subsubsection{Segmentation}

The mean segmentation rate is morealtered in the patients exposed to formaldehydes (53;9\% vs 69.1\%; p = 0.08). There is a slight association between such exposures and the decrease in the segmentation rate, with for formaldehydes: OR = 1.96; IC95\%; $0.73-5.3$; $\mathrm{p}=0.177$.

\subsubsection{Embryonic Quality}

The rate of type I embryos is significantly reduced in those exposed to cement (44.4\% vs75.5\%; $p=0.009$ ).

The significance for formaldehydes exposure was (44.9\% vs 64.1\%; $p=0.06)$. Moreover, the calculated "Odds Ratio" ratio showed an association between this decrease and exposure to formaldehydes ( $\mathrm{OR}=1.83$; IC95\%; 0.69 - 4.85; $\mathrm{p}=0.21)$ and to heat $(\mathrm{OR}=1.43$; IC95\%; 0.56 - 3.6; $\mathrm{p}=0.45$ ) (Table 3).

\subsubsection{Pregnancies Obtained}

The rate of pregnancies by transfer is slightly decreased in those exposed in comparison with those who are not $(12.1 \%$ vs $16 \%, \mathrm{p}=0.5)$. The specified pregnancy rates for each factor did not reveal any significant difference; however the figures cannot dispute a decrease in the occurrence of pregnancy in the exposed individuals.

\section{DISCUSSION}

This survey studied the association between sperm quality and occupational exposure with a questionnaire that we designed to be used in routine medical consultation. A large number of factors that are toxic to reproduction are already known well but they are not systematically investigated in the course of a reproductive medicine consultation. The questionnaire is carried out according to the occupational doctor and the reproductive medicine specialist. Furthermore, all the interviews were carried out by the same occupational doctor. This questionnaire is based on sperm characteristics (that is, on the particulars as for quantitative and qualitative aspects of the testicular function) whereas, other measurements of male fertilization (such as fertilization and pregnancy rates) are also dependent on the female partner.

In order to minimize errors, the interviews are achieved without prior knowledge of the findings of the sperm test. In addition, all the subjects are enrolled in the same medical center and all the sperm specimens are collected and studied with a standardized protocol. However, one must bear in mind that several limits are taken into account at the time when the results are interpreted. First of all, the exclusion of the subjects with lack of information can be accompanied by the exclusion of some occupations and/or the occupational exposure to

Table 3. Comparison of average rates of embryos of type I (E1) obtained between exposed and non-exposed.

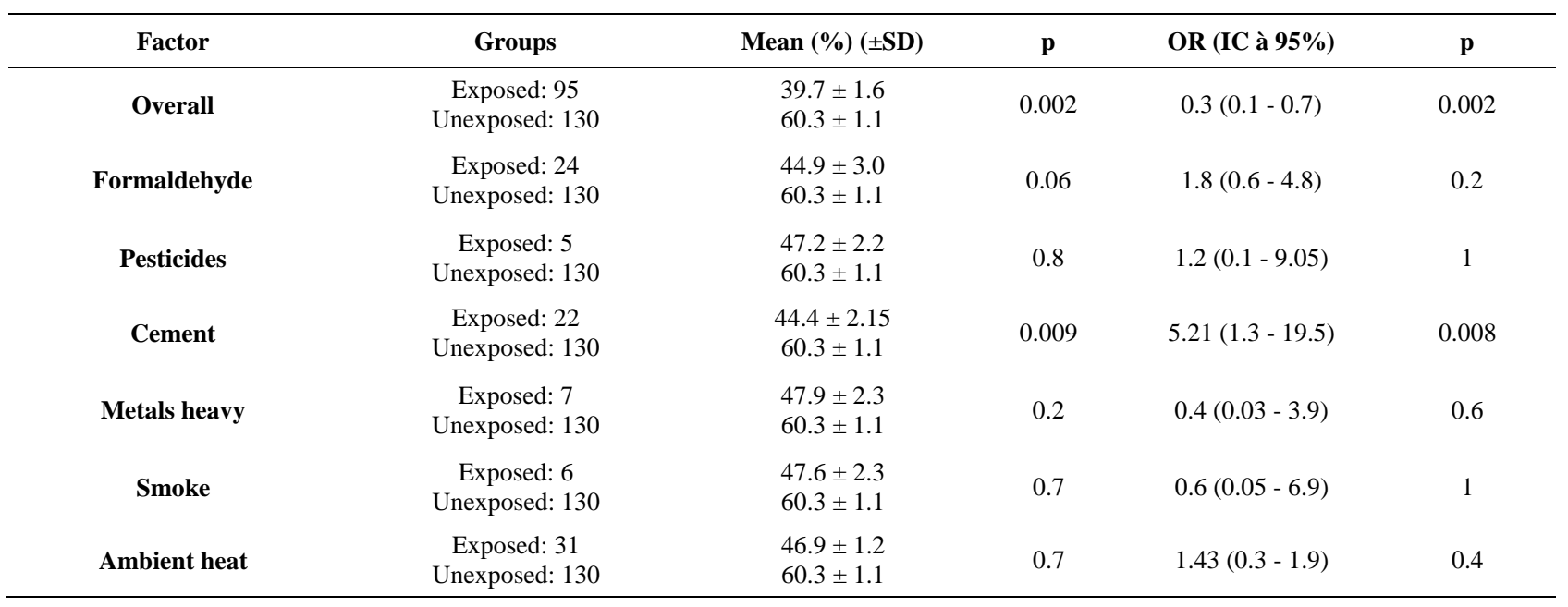

"p: seuil significance $\leq 5 \%$. 
agents likely to be toxic for reproduction. Secondly, the retrospective data collection might introduce a detour of data although there is no suspicion whether there is a difference between the subjects with normal sperm and those with altered sperm. Eventually, this questionnaire was designed according to scientific data available at a given time. Various exposure ways are considered for a statistical analysis based on the types of exposure. However, most documents provide results for current exposures as well as for ancient ones. The exposure to chemicals was analyzed both for the ancient and the present one since their actions might alter the present spermatogenesis (that is, in the last 3 months) such as the stem cells: spermatogonia [20] resulting in spermatogenesis alteration. Recent data have suggested that increasing exposure to endocrine disruptors might lead to problems of male reproductive health, including alteration of sperm quality [21]. The alteration of the sperm parameters related to physical factors, like heat, should stop after the end of exposure [22].

We found associations between sperm quality and occupational exposure to chemicals such as heavy metals, formaldehydes, fumes, pesticides, especially when the exposure was considered dichotomous. More accurate analysis of each sperm parameter confirmed the higher risk of asthenospermia in the subjects exposed to heavy metals [23], but the findings of these analyses did not correspond to higher risks of oligospermia and teratospermia previously reported in these subjects [24]. The effects of formaldehydes and fumes on sperm quality were compatible with previous findings [25]. It must be noted that, in our sample, males with normal sperm were not exposed to plastic vapor or vegetables steam. The statistical analyses are not achieved because of the small size of this group. In the patients exposed to formaldehydes, the increased risk of oligospermia was consistent with the previous results [26] but we did not find any relations between exposure to formaldehydes and teratospermia [27]. Finally, we noticed that individuals exposed to cement had a higher risk of sperm alteration, particularly a higher risk of asthenospermia and teratospermia. Very few previous data were found in the literature as for the relationship between the alteration of the sperm parameters and cement. Cement has a complex composition and several types contain heavy metals. Besides, most individuals exposed to cement are bricklayers, therefore they are also exposed to other chemicals known for their adverse effect on sperm quality (for example: solvents). In the future studies, exposure characterization will be improved thanks to an accurate questionnaire on the use and composition of cement. In the course of the interview, it was easy for the physician to identify exposure to cement. Many patients were able to state that they were exposed to other chemicals like glue or resin without giving details about this product.

The current study underlined the effects of rare physical risk factors. In comparison with previous results, we found more subjects with asthenospermia when they were exposed to excessive heat [28] and with a higher risk of asthenospermia if the exposure was long [6]. Four hypotheses can explain why physical agents are not associated to sperm alteration: 1) lack of effect because of small sampling, 2) incorrect data about exposure, 3) exposure was below the effectiveness threshold or 4) a specific action of the physical agents on some sperm parameters and not on the overall sperm quality. In the second part, that dealt with the effect of some physical and chemical occupational exposures on ICSI results, we observed a decrease in the rates of fertilization, segmentation, E1 embryos and pregnancies in the exposed subjects compared to the non exposed ones. This decrease is statistically significant for formaldehydes and cement. These chemicals might influence the fertilizing capacity of the exposed subjects' spermatozoa. This impact might occur on the genetic material of the spermatozoa and lead to sperm DNA fragmentation. Although the ICSI operator tends to choose a normal motile spermatozoon for injection, this spermatozoon can be considered as "normal" but can have DNA anomalies and will result in fertilization failure.

In order to optimize the choice of the spermatozoa injected in the plasma of the oocytes, these spermatozoa can be chosen under great enlargement for a better injection of morphologically selected spermatozoa (IMSI) so as to ensure a higher pregnancy rate [29]. However, this technique is both recent and requires much hindsight before it can be recommended routinely. In IVF, the fertilizing spermatozoon can be selected by the zonapellucida which may reject cases of aneuploidy [30].

The occupational exposure to chemical and physical products presented in this survey is one of the environmental causes of sperm DNA fragmentation. Several other causes can be considered, particularly chemotherapy, air pollution, tobacco, the protocols of preparing the spermatozoa for IVF or ICSI. The reactive species (ROS) of oxygen which result from this occupational exposure can be a major factor of rupture of the DNA strands. Sperm DNA fragmentation can also be due to a series of pathological conditions, including cryptorchidism, cancer, varicocele, fever, age, infection and leucospermia. In case of varicocele, the treatment of this disease might reduce the DNA fragmentation rate [31].

\section{CONCLUSIONS}

Thanks to the collaboration between occupational doctors and reproductive medicine specialists, this study showed the associations between the occupational exposure and the sperm parameters. This represents a prom- 
ising approach for the reprotoxic evaluation of the occupational exposure. Covering most risk factors at work, it would allow quantifying the impact of these factors on a large population in the framework of the couple's infertility. Furthermore, the questionnaire could be used to investigate certain additional associations between the alteration of the sperm quality and exposures as was the case with exposure to cement.

In the future, continuous collaboration between hygiene and reproductive health is necessary for individual and collective prevention. Finally, this procedure allows the patients treated in the reproductive medicine unit to become aware of the relationships between some occupations and the alteration of the sperm quality. Later, we intend to widen the studied population in order to include other physical factors of exposure such as exposures to electromagnetic waves, ionizing radiation, mechanical vibrations etc. and to reach a better characterization of the exposure. The use of the sperm DNA fragmentation is a reliable means of assessing the effect of occupational exposure on the quality of the spermatozoa and on their fertilizing capacity.

The search for associations between occupational exposure and ICSI results did not show any significant difference for all the factors studied. In this case, it was of course difficult to draw conclusions because the literature did not present studies trying to identify the proper effect of gonadotoxic factors on the results of ICSI. Moreover, the important part that women have in the fertilization phenomenon and the multitude of hazards were a considerable contingency to take into consideration.

\section{ACKNOWLEDGEMENTS}

This work was supported by the budget of the laboratory of cytogenetic, molecular Biology and Human reproductive Biology under the code "LR 03 SP 02".

\section{CONFLICT OF INTERESTS}

The author has declared that no conflict of interest exists.

\section{REFERENCES}

[1] Mosher, W.D. and Pratt, W.F. (1991) Fecundity and infertility in the United States: Incidence and trends. Fertility and Sterility, 56, 192-193.

[2] Skakkebaek, N.E., Giwercman, A. and de Kretser, D. (1994) Pathogenesis and management of male infertility. Lancet, 343, 1473-1478. http://dx.doi.org/10.1016/S0140-6736(94)92586-0

[3] Stoy, J., Hjollund, N.H., Mortensen, J.T., et al. (2004) Semen quality and sedentary work position. International Journal of Andrology, 27, 5-11. http://dx.doi.org/10.1046/j.0105-6263.2003.00428.x
[4] Kurinczuk, J.J. and Clarke, M. (2001) Case-control study of leatherwork and male infertility. Occupational and Environmental Medicine, 58, 217-224. http://dx.doi.org/10.1136/oem.58.4.217

[5] Welch, L.S., Schrader, S.M. and Turner, T.W. (1988) Effects of exposure to ethylene glycol ethers on shipyard painters: II. Male reproduction. American Journal of Industrial Medicine, 14, 509-526. http://dx.doi.org/10.1002/ajim.4700140503

[6] Bujan, L., Daudin, M., Charlet, J.P., et al. (2000) Increase inscrotal temperature in car drivers. Human Reproduction, 15, 1355-1357. http://dx.doi.org/10.1093/humrep/15.6.1355

[7] Gracia, C.R., Sammel, M.D., Coutifaris, C., et al. (2005) Occupational exposures and male infertility. American Journal of Epidemiology, 162, 729-733. http://dx.doi.org/10.1093/aje/kwi269

[8] Wong, W.Y., Zielhuis, G.A., Thomas, C.M., et al. (2003) New evidence of the influence of exogenous and endogenous factors on sperm count in man. European Journal of Obstetrics \& Gynecology and Reproductive Biology, 110, 49-54. http://dx.doi.org/10.1016/S0301-2115(03)00162-3

[9] Guo, Y.L., Hsu, P.C., Hsu, C.C., et al. (2000) Semen quality after prenatal exposure to polychlorinated biphenyls and dibenzofurans. Lancet, 356, 1240-1241. http://dx.doi.org/10.1016/S0140-6736(00)02792-6

[10] Rignell-Hydbom, A., Rylander, R., Giwercman, A., et al. (2004) Exposure to CB-153 and p,p0-DDE and male reproductive function. Human Reproduction, 19, 20662075. http://dx.doi.org/10.1093/humrep/deh362

[11] Elzanaty, S., Richthoff, J., Malm, J., et al. (2002) The impact of epididymal and accessory sex gland function on sperm motility. Human Reproduction, 17, 2904-2911.

[12] Richthoff, J., Spano, M., Giwercman, Y.L., et al. (2002) The impact of testicular andaccessory sex gland function on sperm chromatin integrity as assessed bythe sperm chromatin structure assay (SCSA). Human Reproduction, 17, 3162-3169. http://dx.doi.org/10.1093/humrep/17.12.3162

[13] Enmark, E., Pelto-Huikko, M., Grandien, K., et al. (1997) Human estrogen receptor bgenestructure, chromosomal localization and expression pattern. Journal of Clinical Endocrinology and Metabolism, 82, 4258-4265.

[14] Arbuckle, T.E. and Sever, L.E. (1998) Pesticide exposures and fetal death: A review of the epidemiologic literature. Critical Reviews in Toxicology, 28, 229-270. http://dx.doi.org/10.1080/10408449891344218

[15] WHO (1999) WHO laboratory manual for examination of human semen and sperm-Cervical mucus interaction. CUP, Cambridge.

[16] David, G., Bisson, J.P. and Czyglic, F. (1975) Anomalies morphologiques du spermatozoïde humain 1) propositions pour un système declassification. Journal de Gynécologie, Obstétrique et Biologie de la Reproduction, 4, 17-36.

[17] Jouannet, P., Ducot, B., Feneux, D., et al. (1988) Male factors and the likehood of pregnancy in infertile couples. 
I. Study of sperm characteristics. International Journal of Andrology, 11, 379-384. http://dx.doi.org/10.1111/j.1365-2605.1988.tb01011.x

[18] Englert, Y., Van den Bergh, M., Rodesch, C., et al. (1991) Nouveau programme de fécondation in vitro à l'hôpital erasme: Premiers résultats originaux. Revue Médicale de Bruxelles, 12, 305-314.

[19] Puissant, F., Van Rysselberge, M., Barlow, P., et al. (1987) Embryo sconing as a pronostic tool in IVF treatment. Human Reproduction, 2, 705-708.

[20] Keck, C., Bergmann, M., Ernst, E., et al. (1993) Autometallographic detection of mercury in testicular tissue of aninfertile man exposed to mercury vapor. Reproductive Toxicology, 7, 469-475. http://dx.doi.org/10.1016/0890-6238(93)90092-L

[21] Skakkebæk, N.E., Jørgensen, N., Main, K.M., et al. (2006) Is human fecundity declining? International Journal of Andrology, 29, 2-11. http://dx.doi.org/10.1111/j.1365-2605.2005.00573.x

[22] Carlsen, E., Andersson, A.M., Petersen, J.H., Skakkebaek, N.E., et al. (2003) History offebrile illness and variation in semen quality. Human Reproduction, 18, 2089-2092. http://dx.doi.org/10.1093/humrep/deg412

[23] Telisman, S., Cvitkovic, P., Jurasovic, J., et al. (2000) Semen quality and reproductive endocrine function in relation tobiomarkers of lead, cadmium, zinc and copper in men. Environmental Health Perspectives, 108, 45-53. http://dx.doi.org/10.1289/ehp.0010845

[24] Sheiner, E.K., Sheiner, E., Hammel, R.D., et al. (2003) Effect of occupational exposures on male fertility: Literature review. Industrial Health, 41, 55-62. http://dx.doi.org/10.2486/indhealth.41.55

[25] Cherry, N., Moore, H., McNamee, R., et al. (2008) Participating centres of Chaps-UK, Occupation and male in- fertility: Glycol ethers and other exposures. Occupational and Environmental Medicine, 65, 708-714.

http://dx.doi.org/10.1136/oem.2007.035824

[26] Gaspari, L., Chang, S.S., Santella, R.M., et al. (2002) Polycyclic aromatic hydrocarbon-DNA adducts in human sperm as a marker of DNA damage and infertility. Mutation Research, 535, 155-160. http://dx.doi.org/10.1016/S1383-5718(02)00297-8

[27] Hsu, P.C., Chen, I.Y., Pan, C.H., et al. (2006) Sperm DNA damage correlates with polycyclic aromatic hydrocarbons biomarker in coke-oven workers. International Archives of Occupational and Environmental Health, 79, 349-356. http://dx.doi.org/10.1007/s00420-005-0066-3

[28] Figa Talamanca, I., Dell’Orco, V., Pupi, A., et al. (1992) Fertility and semen quality of workers exposed to high temperatures in the ceramics industry. Reproductive Toxicology, 6, 517-523. http://dx.doi.org/10.1016/0890-6238(92)90036-S

[29] Bartoov, B., Berkovitz, A., Eltes, F., et al. (2003) Pregnancy rates are higher with intracytoplasmic morphologically selected sperm injection than with conventional intracytoplasmic injection. Fertility and Sterility, 80, 1413-1419. http://dx.doi.org/10.1016/j.fertnstert.2003.05.016

[30] Van Dyk, Q., Lanzerdorf, S., Kolm, P., et al. (2000) Incidence of aneuploide spermatozoa from subfertile men: selected with motility versus hemizona bound. Human Reproduction, 15, 1529-1536. http://dx.doi.org/10.1093/humrep/15.7.1529

[31] Saleh, R.A., Agarwal, A., Sharma, R.K., et al. (2003) Evaluation of nuclear DNA damage in spermatozoa from infertile men with varicocele. Fertility and Sterility, 80, 1431-1436.

http://dx.doi.org/10.1016/S0015-0282(03)02211-8 